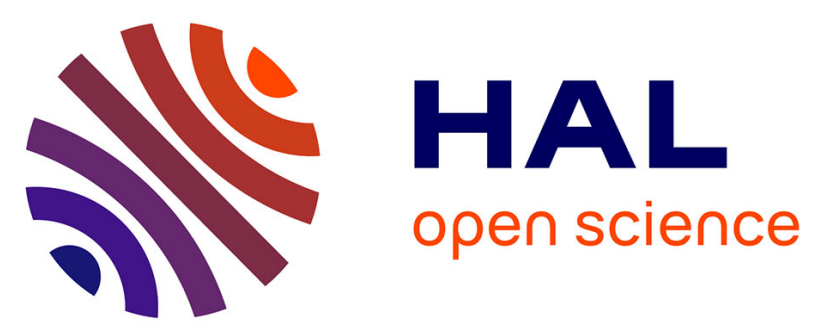

\title{
Highlighting of a local non-equilibrium thermodynamics during the transfer of trichlorethylene (TCE) in the superficial layers of arid soils
}

Samuel Ouoba, Bruno Cousin, David Y. Toguyeni, Salifou. K. Ouiminga, Fabien Cherblanc, Jean Koulidiati, Jean-Claude Benet

\section{To cite this version:}

Samuel Ouoba, Bruno Cousin, David Y. Toguyeni, Salifou. K. Ouiminga, Fabien Cherblanc, et al.. Highlighting of a local non-equilibrium thermodynamics during the transfer of trichlorethylene (TCE) in the superficial layers of arid soils. European Journal of Environmental and Civil Engineering, 2015, 19 (9), pp.1096-1107. 10.1080/19648189.2014.996672 . hal-01306073

\section{HAL Id: hal-01306073 https://hal.science/hal-01306073}

Submitted on 22 Apr 2016

HAL is a multi-disciplinary open access archive for the deposit and dissemination of scientific research documents, whether they are published or not. The documents may come from teaching and research institutions in France or abroad, or from public or private research centers.
L'archive ouverte pluridisciplinaire HAL, est destinée au dépôt et à la diffusion de documents scientifiques de niveau recherche, publiés ou non, émanant des établissements d'enseignement et de recherche français ou étrangers, des laboratoires publics ou privés. 


\title{
Highlighting of a local Non-Equilibrium Thermodynamics during the transfer of trichlorethylene (TCE) in the superficial layers of Arid Soils.
}

\author{
Samuel Ouoba", ${ }^{*}$, Bruno Cousin ${ }^{2}$, David Y. Toguyeni ${ }^{1}$, Salifou K. Ouiminga ${ }^{1}$, Fabien Cherblanc ${ }^{2}$, Jean \\ Koulidiati $^{1}$, Jean-Claude Bénet ${ }^{2}$. \\ ${ }^{1}$ Laboratoire de Physique et de Chimie de l'Environnement, Université de Ouagadougou, UFR-SEA, 03 BP 7021 \\ Ouaga 03, Burkina Faso \\ ${ }^{2}$ Laboratoire de Mécanique et Génie Civil (LMGC), CNRS, Université de Montpellier, Montpellier, France
}

\begin{abstract}
In this paper, we analyze and model -the mass transfer of trichloroethylene in the surface layer of a soil. Our study essentially focuses on arid soils taking into account the phase change liquid-vapor. We have then examined the validity of the assumption of local equilibrium by comparing the values of the instantaneous pressure of the trichloroethylene vapor and the equilibrium vapor pressure during the transfer process. It appears that the assumption of local equilibrium during the transfer of trichloroethylene cannot be admitted.
\end{abstract}

Keywords: transfer; non-equilibrium; trichloroethylene; arid soil; phase change.

* Corresponding author: 03 BP 7021 LPCE/UFR-SEA Université de Ouagadougou (Burkina Faso) 03.

Tel.: (+226) $70130301 /$ / (+226) 76671557

E-mail address : samuel_ouoba1@yahoo.fr (Samuel Ouoba) 


\section{Nomenclature}

\begin{tabular}{|c|c|c|}
\hline$C_{T}$ & TCE concentration in aqueous phase & $\left(\mathrm{kg} \cdot \mathrm{m}^{-3}\right)$ \\
\hline$C_{T 0}$ & TCE initial concentration in aqueous phase & $\left(\mathrm{kg} \cdot \mathrm{m}^{-3}\right)$ \\
\hline$D_{T}^{a}$ & Diffusion coefficient of TCE vapor in air & $\left(\mathrm{m}^{2} \mathrm{~s}^{-1}\right)$ \\
\hline$D_{T}^{W}$ & Diffusion coefficient of TCE in water & $\left(\mathrm{m}^{2} \mathrm{~s}^{-1}\right)$ \\
\hline$D_{w}^{a}$ & Diffusion coefficient of water vapor in air & $\left(\mathrm{m}^{2} \mathrm{~s}^{-1}\right)$ \\
\hline$g$ & Acceleration of gravity & $\left(\mathrm{m}^{2} / \mathrm{s}\right)$ \\
\hline$J_{T}$ & Evaporation flux of TCE & $\left(\mathrm{kg} \mathrm{m}^{-2} \mathrm{~s}^{-1}\right)$ \\
\hline$J_{w}$ & Evaporation flux of water & $\left(\mathrm{kg} \mathrm{m}^{-2} \mathrm{~s}^{-1}\right)$ \\
\hline$K_{n s}$ & Permeability of liquid phase in soil & $(\mathrm{m} / \mathrm{s})$ \\
\hline$K_{\text {sat }}$ & Saturation permeability of liquid in soil & $(\mathrm{m} / \mathrm{s})$ \\
\hline$L_{H}$ & Evaporation coefficient of heptane & $\left(\mathrm{kg} \mathrm{K} \mathrm{s} \mathrm{m}^{-5}\right)$ \\
\hline$L_{T}$ & Evaporation coefficient of TCE & $\left(\mathrm{kg} \mathrm{K} \mathrm{s} \mathrm{m}^{-5}\right)$ \\
\hline$L_{w}$ & Evaporation coefficient of water & $\left(\mathrm{kg} \mathrm{K} \mathrm{s} \mathrm{m}^{-5}\right)$ \\
\hline$M_{H}$ & Molar weight of heptane & $\left(\mathrm{kg} \mathrm{mol}^{-1}\right)$ \\
\hline$M_{T}$ & Molar weight of TCE & $\left(\mathrm{kg} \mathrm{mol}^{-1}\right)$ \\
\hline$M_{w}$ & Molar weight of water & $\left(\mathrm{kg} \mathrm{mol}^{-1}\right)$ \\
\hline$P_{H}^{e q}$ & Equilibrium vapor pressure of heptane & $(\mathrm{Pa})$ \\
\hline$P_{H}^{v}$ & Vapor pressure of heptane & $(\mathrm{Pa})$ \\
\hline$P_{T}^{e q}$ & Equilibrium vapor pressure of TCE & $(\mathrm{Pa})$ \\
\hline$P_{T}^{v}$ & Vapor pressure of TCE & $(\mathrm{Pa})$ \\
\hline$P_{w}^{v}$ & Vapor pressure of water & $(\mathrm{Pa})$ \\
\hline$P_{w}^{e q}$ & Equilibrium vapor pressure of water & $(\mathrm{Pa})$ \\
\hline$R$ & Ideal gas constant & $\left(\mathrm{J} \mathrm{K}^{-1} \mathrm{~mol}^{-1}\right)$ \\
\hline$v_{L}$ & Barycentric velocity of liquid phase & $(\mathrm{m} / \mathrm{s})$ \\
\hline$w_{L}$ & Liquid content & $(\%)$ \\
\hline$w_{L}^{r}$ & Residual liquid content & $(\%)$ \\
\hline$w_{L}^{\text {sat }}$ & Saturation liquid content & $(\%)$ \\
\hline$w_{L 0}$ & Initial liquid content & $(\%)$ \\
\hline$w_{0}$ & Initial water content & $(\%)$ \\
\hline$\phi_{\mathrm{g}}$ & Volume fraction of gas & $(\%)$ \\
\hline$\rho_{T}^{v}$ & Apparent mass density of TCE vapor & $\left(\mathrm{kg} \mathrm{m}^{-3}\right)$ \\
\hline$\rho_{w}^{L}$ & Apparent mass density of water liquid & $\left(\mathrm{kg} \mathrm{m}^{-3}\right)$ \\
\hline$\rho_{w}^{v}$ & Apparent mass density of water vapor & $\left(\mathrm{kg} \mathrm{m}^{-3}\right)$ \\
\hline$\rho_{T}^{L}$ & Apparent mass density of aqueous phase of TCE & $\left(\mathrm{kg} \mathrm{m}^{-3}\right)$ \\
\hline
\end{tabular}

\section{Introduction}

The description of a pollutant transfer as trichloroethylene in the surface layers of a dry soil deserves the attention of the scientific community regarding the resolution of problems related to environmental sciences (Braida \& Ong, 2000). However, understanding the phenomena involved in the transfer of a compound in a soil is very difficult because many phenomena are coupled during transfer processes in a multiphase medium which can deform, and where the fluid contents can vary in time and space. Accordingly, any modeling used to describe and predict the dynamic behavior of a volatile compound in an arid soil must be preceded by an experimental investigation to determine the essential parameters involved in the phenomena (Auriault \& Lewandowska, 1997). Most bibliographic works use a classical approach to describe mass transfer in soils, assuming that the continuous phase of the porous medium fully and instantaneously participates to the mass transfer (Dridi \& Schäfer, 2006). Such transfer process occurs in the saturated zone of the soil and can be well described by the Darcy's law. In these conditions, it is considered that water is not entirely adsorbed by the solid particles; so that the liquid/vapor equilibrium described by Henry's Law $\left(P_{T}^{e q}=K_{H} C_{T}\right)$ can be applied. However, several studies in the literature showed that the low water contents are responsible of soil hygroscopic effects causing a deviation of the water activity. Recent studies realized on water showed that these effects can modify not only the equilibrium between phases but the kinetics of phase change (Chammari et al., 2003; Ouedraogo et al., 2013). It is therefore logical to wonder if in such circumstances the conventional assumption of equilibrium can still be applied. Otherwise, it becomes necessary to find the suitable way to describe the liquid-vapor phase change dynamics; that is the objective of the present article. 


\section{Materials and Method}

\subsection{Presentation of the System and Definition of Initial Conditions}

The system studied in this work is a portion of soil containing a liquid phase (subscript $L$ ) composed of water (denoted by $w$ ) and dissolved TCE (denoted by $T$ ) and a gas phase (denoted by $g$ ) composed of air (denoted by $a$ ). The physic-chemical properties of TCE and the soil sample are respectively given in Tables 1 and 2 .

Table 1. TCE physic-chemical properties at $30^{\circ} \mathrm{C}$.

\begin{tabular}{ccc} 
Equilibrium vapor pressure $/ \mathrm{Pa}$ & Henry's constant $/ \mathrm{Pa} \mathrm{m}^{3} \mathrm{~mol}^{-1}$ & $\begin{array}{l}\text { Solubility } \\
/ \mathrm{Mg}^{-1} \mathrm{Ire}^{-1}\end{array}$ \\
\hline 11912 & 1195.5 & 1310 \\
\hline
\end{tabular}

Table 2. Main characteristics of the soil.

\begin{tabular}{cccc}
\hline $\begin{array}{c}\text { Particle size } \\
0-2 \mathrm{~mm}\end{array}$ & $\begin{array}{c}\text { Particle density } \\
2650 \mathrm{~kg} .{ }^{-3}\end{array}$ & $\begin{array}{c}\text { Apparent mass } \\
\text { density } 1500 \mathrm{~kg} .\end{array}$ & $\begin{array}{c}\text { Porosity } \\
43 \%\end{array}$ \\
\hline $\begin{array}{c}\text { quartz content } \\
40 \%\end{array}$ & $\begin{array}{c}\text { calcite content } \\
45-50 \%\end{array}$ & $\begin{array}{c}\text { clay content } \\
10 \%\end{array}$ & \\
\hline organic matter & organic carbon & total N & $\mathrm{C} / \mathrm{N}$ \\
$0.28 \%$ & $0.16 \%$ & $0.10 \%$ & 16.83 \\
\hline$w_{L}^{\text {sat }}$ & $w_{L}^{r}$ & $K_{\text {sat }}$ & \\
$28.9 \%$ & $1 \%$ & $3.10^{-5}{\mathrm{~m} . \mathrm{s}^{-1}}$ & \\
\hline
\end{tabular}

Considering the experimental conditions the following assumptions are admitted (Ouoba et al., 2014a):

- A1: the solid phase is chemically inert and incompressible,

- A2:the temperature is uniform and constant,

- A3: the gas behaves as an ideal gas mixture and is assumed to be stationary so that the filtration flux of the gaseous phase is zero,

- A4: the liquid phase is an ideal dilute solution of water and TCE,

- A5: there are no chemical reactions in liquid and gas phase. The only physic-chemical phenomenon taken into account is the liquid-gas phase change of water and TCE,

- A6: the pressure of the gas is uniform, constant and equals to atmospheric pressure,

The previous validation procedures proved the reliability of the theoretical model in the case of pure water; particularly the phase change phenomenon is accurately described by the model (Bénet et al., 2009; Lozano et al., 2008; Ouedraogo et al., 2013). Thus, in this section, dissolved TCE is considered to study the non-equilibrium between the phases. The phenomenological evaporation coefficient has not been experimentally determined for dissolved TCE. That is the reason why as a first approximation, we adopted for the evaporation coefficient of dissolved TCE the same expression than that obtained for pure TCE.

The conditions on water are:

- The initial water content of soil is uniform;

- $\quad$ The relative humidity of air in the chamber is set to $30 \%$ or to $50 \%$.

The tests of simulation have been performed on soil columns with $30 \mathrm{~cm}$ of height and $7.5 \mathrm{~cm}$ of diameter, where the liquid phase is a solution of TCE with a known initial concentration. The problem is considered as onedimensional so that the initial conditions are defined by:

- $w_{L}(t=0, z)=w_{L 0}$

- $\quad P_{w}^{v}(t=0, z)=P_{w}^{v e q}\left(w_{L 0}\right)$

- $\quad C_{T}(t=0, z)=C_{T 0}$

- $\quad P_{T}^{v}(t=0, z)=P_{T}^{v e q}\left(C_{T 0}\right)$ 


\subsection{Basic equations of transfer}

A classic approach of mass balance in a Representative Elementary Volume (REV) provides the equations of transfer of water and TCE in the aqueous phase. We then obtain:

\section{For liquid water}

$\frac{\partial \rho_{w}^{L}}{\partial t}+\underbrace{\nabla\left(\rho_{w}^{L} v_{L}\right)}_{\text {term of filtration }}=\underbrace{-J_{w}}_{\text {phase change }}$

\section{For the vapor of water}

$\frac{\partial \rho_{w}^{v}}{\partial t}-\underbrace{\nabla\left(D_{w}^{a} \nabla \rho_{w}^{v}\right)}_{\text {term of diffusion }}=\underbrace{J_{w}}_{\text {phase change }}$

Where the diffusion coefficient of water vapor in air, given by Ouedraogo et al. (2013) is:

$D_{w}^{a}=2,57 \times 10^{-5} \mathrm{~m}^{2} / \mathrm{s}$.

For the aqueous phase of TCE

$\frac{\partial \rho_{T}^{L}}{\partial t}+\underbrace{\nabla\left(\rho_{T}^{L} v_{L}\right)}_{\text {term of filtration }}-\underbrace{\nabla\left(D_{T}^{w} \nabla \rho_{T}^{L}\right)}_{\text {term of diffusion }}=\underbrace{-J_{T}}_{\text {phase change }}$

Where the diffusion coefficient of TCE in water, given by Mahmoodlu et al. (2014) is:

$D_{T}^{w}=9,1 \times 10^{-6} \mathrm{~m}^{2} / \mathrm{s}$.

\section{For the vapor of TCE}

$\frac{\partial \rho_{T}^{v}}{\partial t}-\underbrace{\nabla\left(D_{T}^{a} \nabla \rho_{T}^{v}\right)}_{\text {term of diffusion }}=\underbrace{J_{T}}_{\text {phase change }}$

Where the diffusion coefficient of TCE in air, given by Mahmoodlu et al. (2014) is:

$$
D_{T}^{a}=7.9 \times 10^{-6} \mathrm{~m}^{2} / \mathrm{s} .
$$

The term of filtration of the liquid phase is given by:

$\rho_{w}^{L} v_{L}=-\frac{K_{n s}}{g}\left(\nabla P_{w}^{L}+\rho_{w}^{L} g\right)$

Where the coefficient of permeability of soil is given by Ouedraogo et al. (2013)

$K_{n s}\left(w_{L}\right)=K_{\text {sat }}\left(\frac{w_{L}-w_{L}^{r}}{w_{L}^{\text {sat }}-w_{L}^{r}}\right)^{\lambda}$

In this relation the coefficient $\lambda=5$

It is important to note that for each compound, the transfers within the two phases are coupled by phase change phenomena through the evaporation rates, $J_{\mathrm{w}}$ and $J_{\mathrm{T}}$ given by Bénet et al. (2009):

$J_{c}=L_{c} \frac{R}{\phi_{\mathrm{g}} M_{c}} \ln \left(\frac{P_{c}^{v}}{P_{c}^{v e q}}\right), \quad c=T, w$

Where $P_{c}^{\text {veq }}$ is given by Ouoba et al. (2010a).

The coefficient of phase change given by Equation (7) has been successfully used by Ouoba et al. (2015) in recent publications. Its determination necessarily requires an experimental study and allows determining the evaporation kinetics. It depends on the state variables (temperature $T$, liquid content $w_{L}$ ), soil properties (composition, texture, compactness, etc.), but no explicit expression is available (Lozano et al., 2008; Ruiz \& Benet, 2001). 


\subsection{Experimental Device and Principle}

The experimental device used to determine the phase change coefficient of a pure liquid in a porous medium is depicted in Figure 1. It was initially developed to measure water activity and has been called "activity-meter". This device and the associated method were validated in our previous works (Ouoba et al., 2014b; Ouoba et al., 2010a) and have been patented in Europe and United States (Bénet et al., 2012)

The sample (a) is placed against a pressure transducer (b) (Druck, PMP4030AB) and a temperature thermocouple (c) (type K). This records the total pressure of the gas, $P_{\mathrm{g}}$, and its temperature, $T$, throughout the test. Data acquisition is performed through a National Instrument DAQ card and analyzed using LabView. A piston pump (d) is placed above the sample to impose a gas pressure below atmospheric pressure. The piston chamber volume is controlled by a screw system (e) with a graduated ruler (f). O-ring gaskets ensure perfect air tightness so that the system can be considered thermodynamically closed. The dimensional characteristics of the device are given by Ouoba et al. (2010b). The whole device is placed in a thermo-regulated bath to ensure a constant temperature. Because the device is made of stainless steel, its high thermal inertia leads to weak temperature variations and thermal equilibrium is experimentally observed.

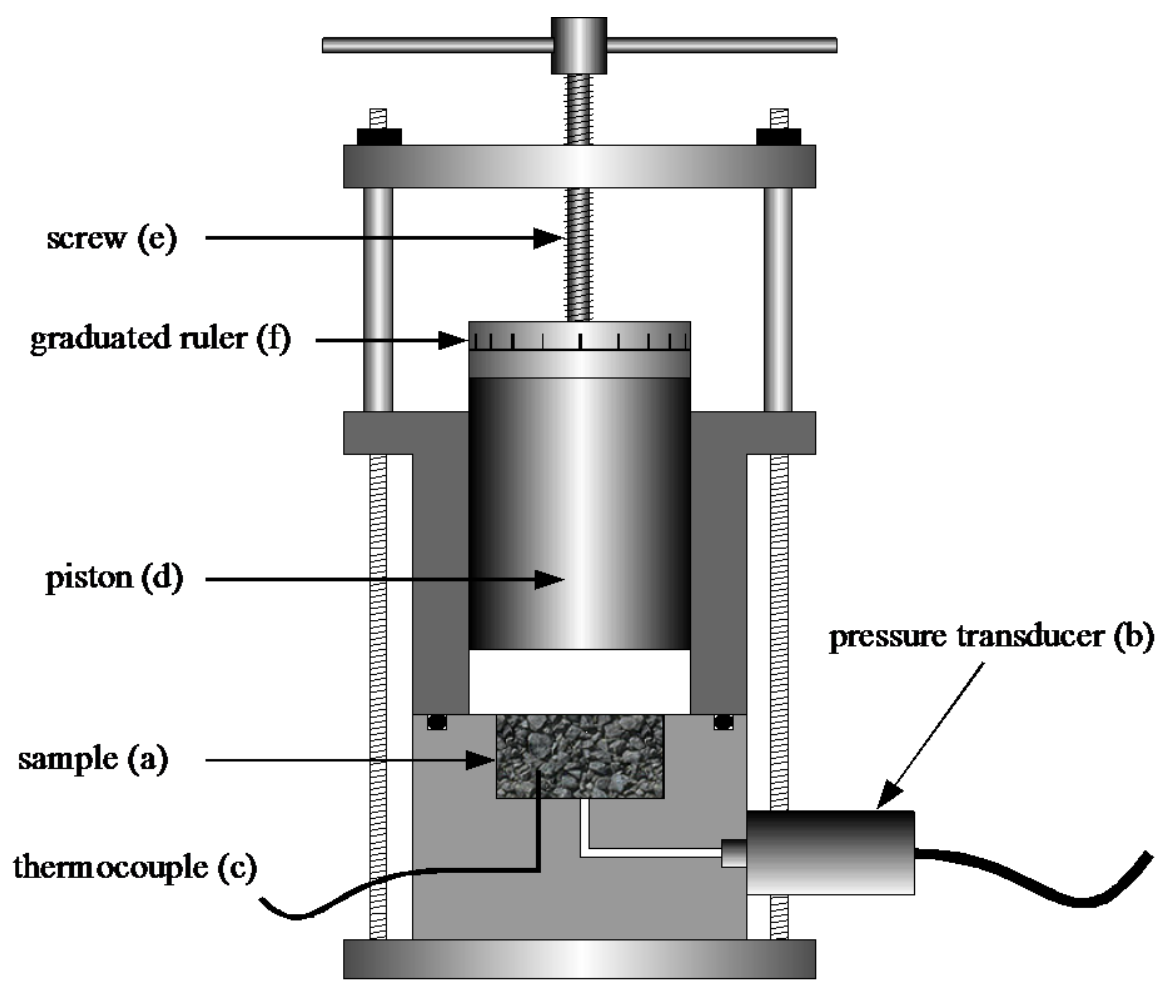

Figure 1. Schematic diagram of the activity-meter.

\section{Results and Discussion}

\subsection{Determination of the evaporation coefficient of TCE}

To describe the hygroscopic effects in the transfer process of a compound in an arid soil, it is necessary to consider the liquid/vapor phase change associated with the transfer of this compound. The method used to determine the evaporation coefficient of TCE is largely developed in Ouoba et al. (2014a). It is based on the principle used by Naon et al. (2013) for heptane and by Ouedraogo et al. (2013) for water. We compare in Figure 2 the evaporation coefficients of water, heptane and TCE. One can see that the evaporation coefficient of water is lower than that of heptane and TCE. The evaporation coefficient of TCE is about 7 times higher than that of heptane. These results are related to the highest volatility of TCE compared to the one of heptane and water. Indeed, it is well known that the higher the volatility of a compound, the greater its saturated vapor pressure. According to literature data (Ouoba et al., 2010b), at the same temperature $P_{w}^{e q}<P_{H}^{e q}<P_{T}^{e q}$ which what is in agreement with the results of Figure 2. 


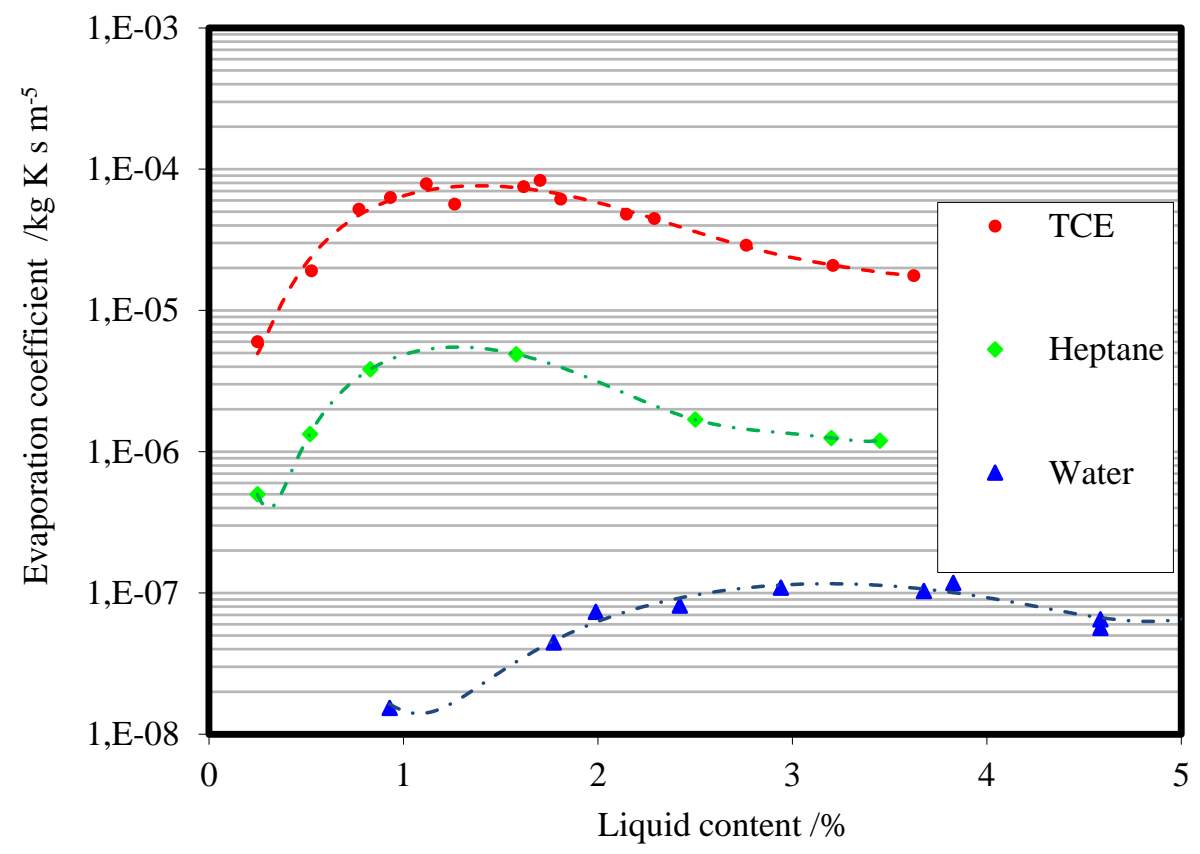

Figure 2. Evaporation coefficients of water, heptane and TCE at $30{ }^{\circ} \mathrm{C}$.

\subsection{Validation of the numerical model}

The validation of the numerical model has concerned water. The transfer equations established for water are discretized by using the following approach:

- An implicit scheme in time;

- An upstream biased for the convection flow diagram;

- Considering the non-linearity of the transfer equations, we chose the Newton-Raphson's method for the numerical solution of the problem.

To validate the numerical model, a comparison has been made between numerical results and experimental results.

The experiments consisted in making soil columns with initial liquid content $w_{\mathrm{L}}$ compacted in PVC (Figure 3). These soil columns were placed in a climatic chamber where temperature and relative humidity were controlled. The columns were let to evolve in the climatic chamber for various experimental drying times. The samples were then removed from the chamber and sliced in order to determine the water content profiles corresponding to a given drying time. 


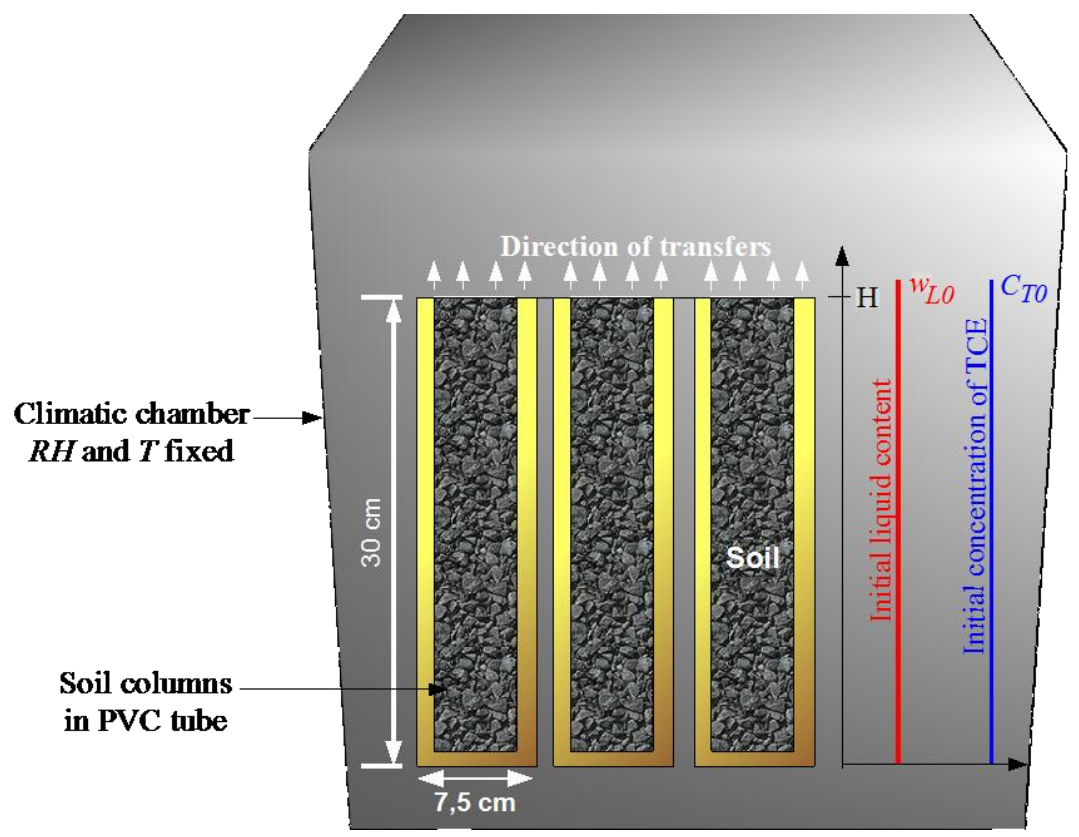

Figure 3. Climate chamber containing soil samples.

The experimental and numerical drying kinetics for two values of the relative humidity, namely $R H=30 \%$ and $R H=50 \%$, are presented in Figure 4. This figure represents the average water content of the sample as a function of time. We can notice that there is a good agreement between experimental and simulated curves.

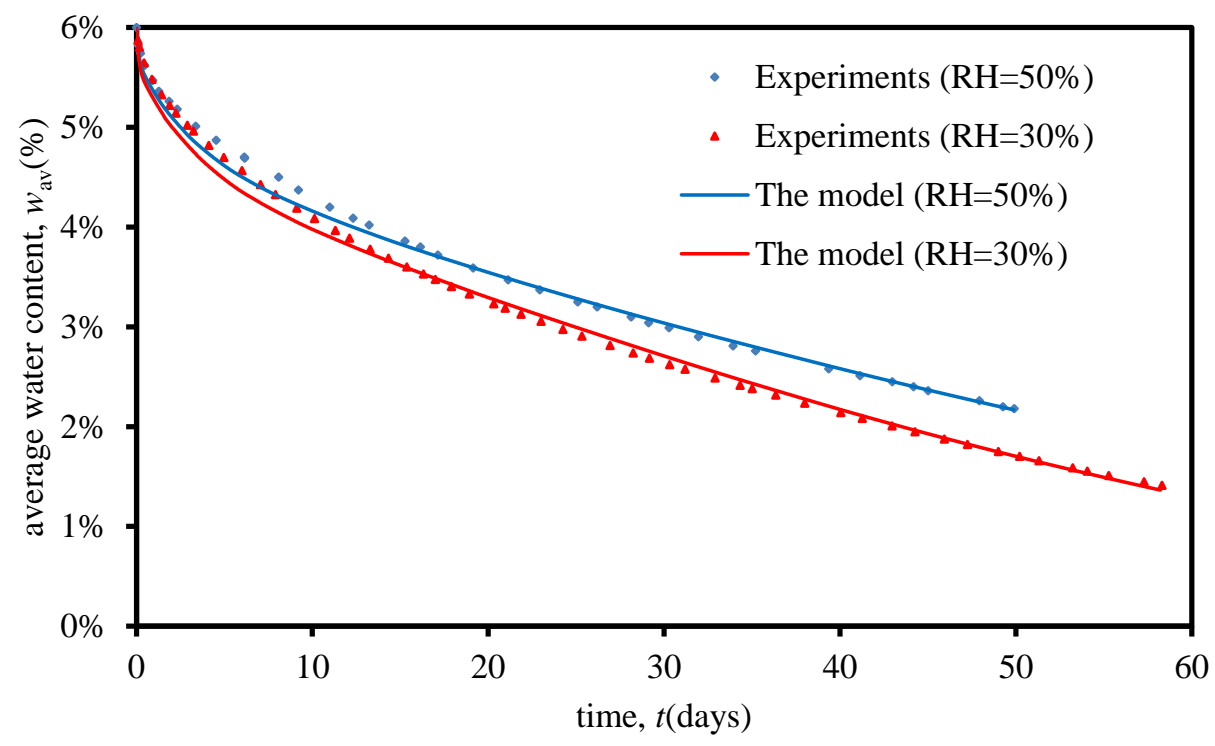

Figure 4. Kinetics of drying for an initial water content $w_{0}=6 \%$ and for two values of relative humidity $R H=50 \%$

$$
\text { and } \mathrm{RH}=30 \% \text {. }
$$

Figure 5 presents the experimental and simulated water content profiles. It may also be noted in this figure that there is a good agreement between both profiles. The differences in the vicinity of the surface may be partly due to possible imperfections of the model but also to errors of measurement during the extraction of the sample and its destruction for measurement.

The profiles highlight a rapid drying front at the beginning of the experience, but much more important near the surface. The examination of the numerical results also shows a significant decrease in water content in the vicinity of the surface a few hours after the starting of the experiment. This value of water content reaches immediately the equilibrium moisture content $(0.24 \%)$ and remains constant as shown by all the curves that admit a common point 
at the surface. At the beginning of drying, the water content in the lower part of the column increases above the initial water content due to gravitational drainage. This phenomenon is accurately predicted by the theoretical model. As the numerical results are in good agreement with experiments for water, the model has been used to describe the transfer of dissolved TCE using the evaporation coefficient of pure TCE.

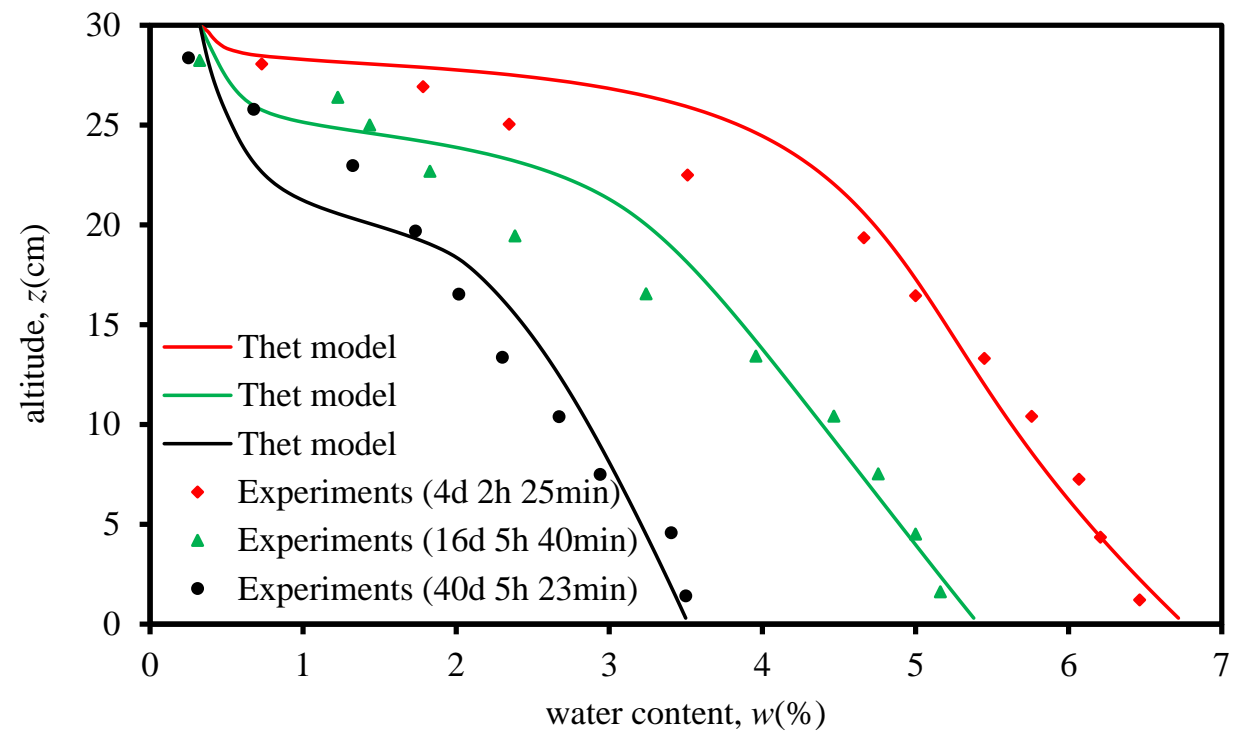

Figure 5. Profiles of water content for $\mathrm{RH}=30 \%$.

\subsection{Highlighting of a thermodynamic non-equilibrium between liquid and vapor phases}

The curves of Figure 6 present an instantaneous vapor pressure profile of TCE, $P_{T}^{v}$, and the corresponding equilibrium vapor pressure profile,$P_{T}^{v e q}$. The two curves are significantly different which means there is not equilibrium between the dissolved TCE and its vapor.

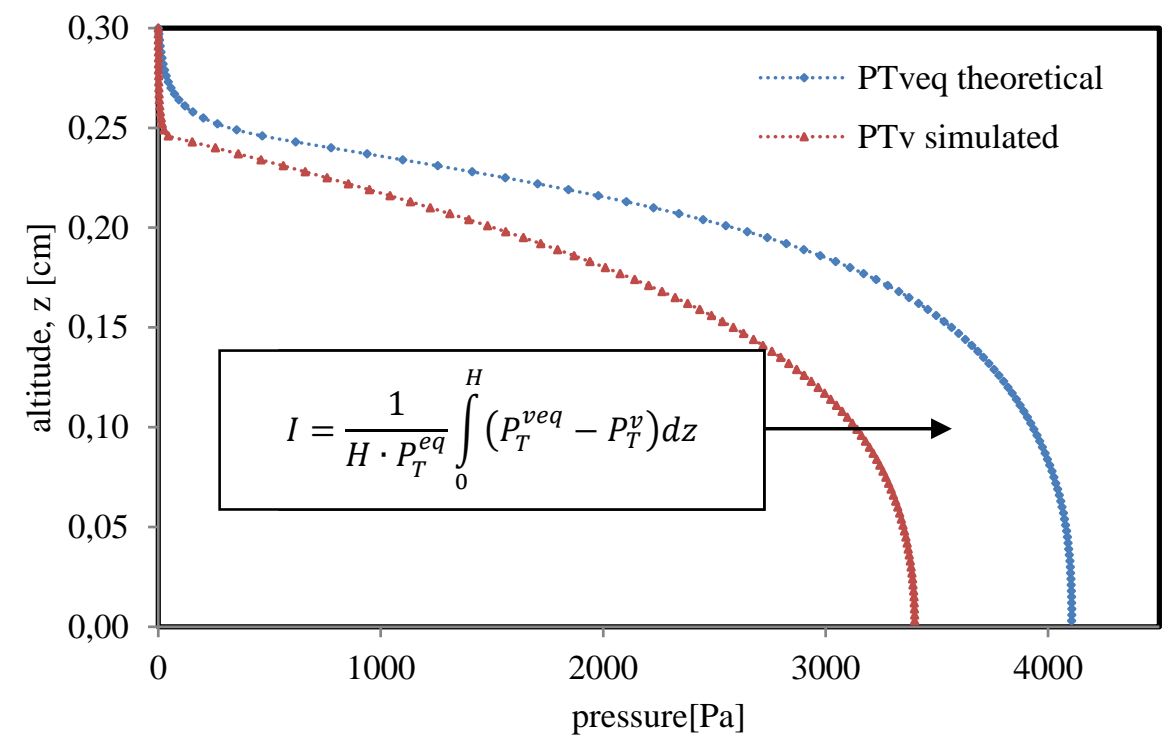

Figure 6. Values of the pressures $P_{T}^{v}[\mathrm{~Pa}]$ and $P_{T}^{e q}[\mathrm{~Pa}]$ for a time $\mathrm{t}=500,000 \mathrm{~s}$ for $w_{0}=3 \%$ and $C_{T 0}=1000 \mathrm{~g} / \mathrm{L}$.

Similar results have been found for other simulation times. Hence, the only parameter that may be responsible of this disequilibrium is the coefficient of phase change. To investigate the influence of the evaporation coefficient of dissolved TCE on the disequilibrium and to better understand the conditions under which the assumption of local 
equilibrium could be admitted, simulations were performed multiplying the evaporation coefficient of pure TCE by a factor $\alpha$ ranging from $10^{-4}$ to $10^{2}$. The parameter chosen to quantify the disequilibrium is:

$I=\frac{1}{H \cdot P_{T}^{v e q}} \int_{0}^{H}\left(P_{T}^{v e q}-P_{T}^{v}\right) d z$

This integral is a dimensionless representation of the area between the curves $P_{T}^{v}$ and $P_{T}^{v e q}$ (Figure 6). So, Figures $\mathbf{7}$ and $\mathbf{8}$ represent the variation of $I$ as a function of $\alpha$ for different values of water contents. Figure $\mathbf{7}$ corresponds to a relative humidity of $30 \%$ and for an initial concentration $C_{T O}=100 \mathrm{mg} / \mathrm{L}$ and Figure 8 is obtained for a relative humidity of $50 \%$ and for an initial concentration $C_{T 0}=1 \mathrm{mg} / \mathrm{L}$.

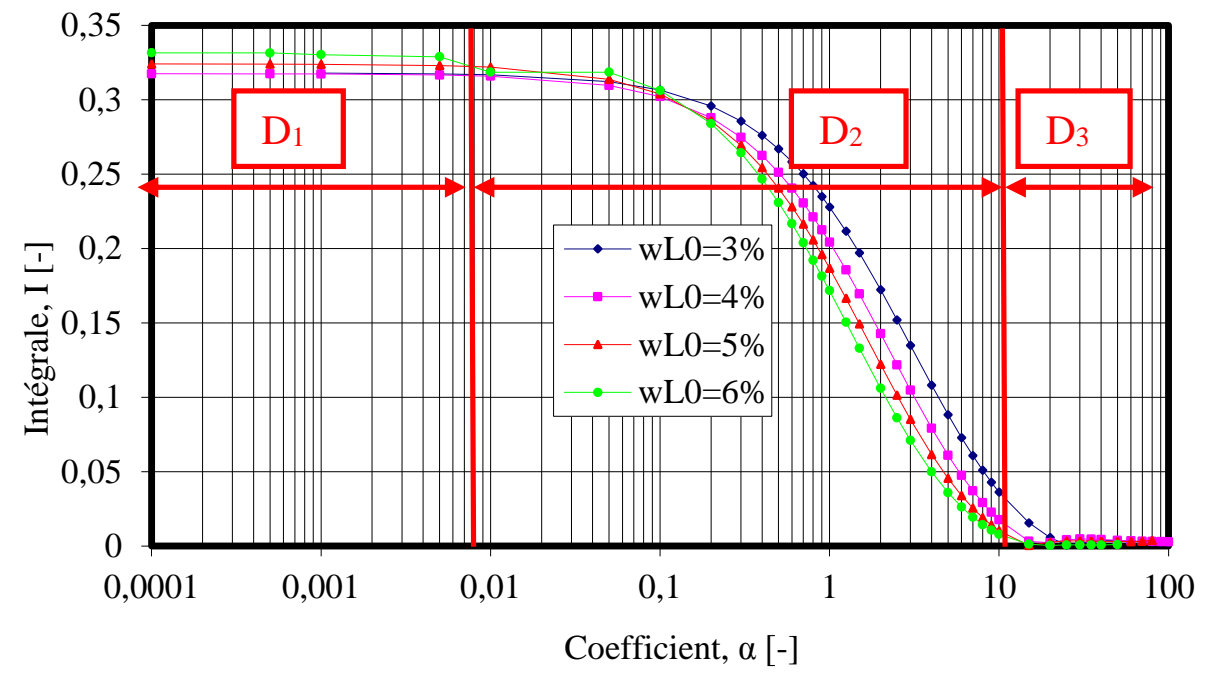

Figure 7. I value as a function of $\alpha$ for $R H=30 \%$ and $C_{T 0}=100 \mathrm{mg} / \mathrm{L}$.

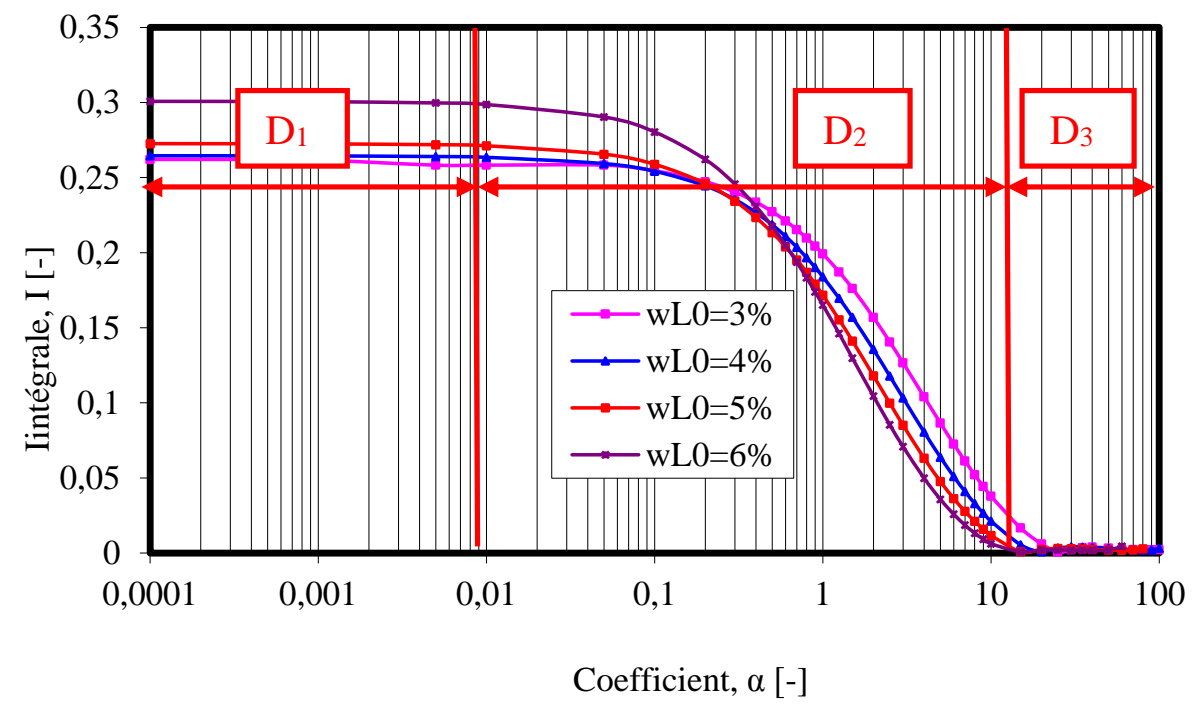

Figure 8. I value as a function of $\alpha$ for $R H=50 \%$ and $C_{T 0}=1 \mathrm{mg} / \mathrm{L}$.

Both Figures highlight the existence of three domains:

- A first domain called $\boldsymbol{D}_{\mathbf{1}}$ in the interval $10^{-4} \leq \alpha \leq 10^{-2}$ where the dimensionless integral $I$ has a value substantially equal to 0.325 . Within this interval it is not possible to apply the local equilibrium assumption. 
Because of the low value of the evaporation coefficient, the transfers are mainly due to capillary actions and surface evaporation,

- A second domain designated by $\boldsymbol{D}_{\mathbf{2}}$ in the interval $10^{-2} \leq \alpha \leq 13$ where $0,325 \leq I<0$. The disequilibrium decreases but the assumption of the local equilibrium is still not applicable. The mechanisms of phase change are fairly low and all the transfer phenomena are competing,

- $\quad$ A third domain $\boldsymbol{D}_{\mathbf{3}}$ for $\alpha>13$ where the value of the dimensionless integral $I$ is almost zero. In this interval, the values of $P_{T}^{v}$ and $P_{T}^{v e q}$ are the same and the instantaneous equilibrium is reached.

These results have shown that the local equilibrium cannot be admitted in the modeling of TCE transfer in an arid soil. It is unlikely that the evaporation coefficient of dissolved TCE would be 13 times higher than that of pure TCE. It is rather likely that, for dissolved TCE, coefficient $\alpha$ is lower than 1.

\section{Conclusion}

In this study, the kinetics of phase change has been characterized for water, heptane and TCE confirming other studies realized on water, i.e., the return to equilibrium is not instantaneous. We have shown that the nonequilibrium is due to the phase change kinetics and we experimentally determined the evaporation coefficient of water, TCE and heptane. From these experiments, explicit expressions of these characteristics have been identified and introduced in a numerical model. The results for water obtained on soil columns with $30 \mathrm{~cm}$ of height and $7.5 \mathrm{~cm}$ of diameter were compared with the results of the model. This confrontation between the experiments and the model has shown that the proposed model can be used to describe the transfer of water in the soil taking into account the phase change. As the numerical results are in good agreement with experiments for water, the model has been used to describe the transfer of TCE in the aqueous phase of soil. The numerical results have shown that during transfer of TCE in the aqueous phase, there is a substantial difference between the actual vapor pressure of TCE, $P_{T}^{v}$, and the equilibrium vapor pressure, $P_{T}^{v e q}$, so the assumption of local equilibrium commonly accepted in the literature is not admitted here for TCE. However, awaiting for other researches in other experimental conditions, the results presented in the present work are only valid when the transport of TCE is performed under the same conditions with the same assumptions as these admitted in this work.

The contribution of this work has enabled to highlight the importance of phase change on transport of volatile organic compound in hygroscopic soil. However, additional studies need to be extended to other types of soils with different physic-chemical characteristics in order to confirm the results of this work. It would also be desirable to undertake a large-scale study on soil columns and in situ by taking into account more experimental variables such as coupling phenomena and variation of porosity in the medium that can help to improve the numerical model. Finally, it would be important to include in the numerical model most of the mechanisms involved in the transport processes such as chemical reactions, photo-degradation...

\section{Acknowledgments}

This work was done within the framework of collaboration between the University Montpellier 2, France and the University of Ouagadougou, Burkina-Faso and supported by the French Ministry of Foreign affairs.

\section{References}

Auriault, J.L., Lewandowska, J. (1997). Effective diffusion coefficient: from homogenization to experiment. Transport in Porous Media, 27, 205-223.

Bénet, J.-C., Cousin, B., Cherblanc, F., \& Ouoba S. (2012). Device for measuring the activity of a liquid in a complex medium and associated method. United States Patent Application Publication, Pub. $n^{\circ}$ US $20120266663 A 1$.

Bénet, J.-C., Lozano, A.L., Cherblanc, F., \& Cousin B. (2009). Phase Change of Water in a Hygroscopic Porous Medium. Phenomenological Relation and Experimental Analysis for Water in soil. Journal of Non-Equilibrium Thermodynamics, 34, 97-117.

Braida, W., \& Ong, S.K. (2000). Influence of Porous Media and Airflow Rate on the Fate of NAPLs Under Air Sparging. Transport in Porous Media, 38, 29-42.

Chammari, A., Naon, B., Cherblanc, F., \& Bénet J.-C. (2003). Transfert d'eau en sol aride avec changement de phase. Comptes Rendus Mécanique, 331, 759-765. 
Dridi, L, \& Schäfer, G. (2006). Quantification du flux de vapeurs de solvants chlorés depuis une source en aquifère poreux vers l'atmosphère : Biais relatifs à la non uniformité de la teneur en eau et à la non stationnarité du transfert. Comptes Rendus Mécanique, 334, 11-20.

Lozano, A., Cherblanc, F., Cousin, B., \& Benet J.-C. (2008). Experimental study and modelling of water phasechange kinetics in soils. European Journal of Soil Science, 59, 939-949.

Mahmoodlu, M. G., Hassanizadeh, S. M., Hartog N., \& Raoof A. (2014). Oxidation of trichloroethylene, toluene, and ethanol vapors by a partially saturated permeable reactive barrier. Journal of Contaminant Hydrology 164, 193-208

Naon, B., Bénet, J.-C., Cousin, B., Cherblanc, F., \& Chammari A. (2013). Evaporation of a volatile organic compound in a hygroscopic soil - influence of the airflow and its VOC vapor saturation. European Journal of Environmental and Civil Engineering, 17, 46-63.

Ouedraogo, F., Cherblanc, F., Naon, B., \& Bénet, J.-C. (2013). Water transfer in soil at low water content. Is the local equilibrium assumption still appropriate? Journal of Hydrology, 492, 117 - 127.

Ouoba, S., Daho, T., Cherblanc, F., Koulidiati, J., \& Bénet, J.-C. (2014a). A New Experimental Method to Determine the Evaporation Coefficient of Trichloroethylene (TCE) in an arid soil. Transport in Porous Media, DOI: 10.1007/s11242-014-0404-6.

Ouoba, S., Cousin, B., Cherblanc, F., Koulidiati, J., \& Bénet, J.-C. (2014b). Une méthode mécanique pour déterminer la porosité totale d'un sol. Comptes Rendus Mécanique, DOI: 10.1016/j.crme.2014.07.003.

Ouoba, S., Cousin, B., Cherblanc, F., \& Bénet, J.-C. (2010a). Une méthode mécanique pour mesurer la pression de vapeur d'équilibre de l'eau dans un milieu complexe. Comptes Rendus Mécanique, 338, 113-119.

Ouoba, S., Cherblanc, F., Cousin, B., \& Bénet, J.C-. (2010b). A New Experimental Method to Determine the Sorption Isotherm of a Liquid in a Porous Medium. Environmental Science and Technology, 44, 5915-5919.

Ruiz, T., \& Benet, J.-C. (2001). Phase-change in a heterogeneous medium: Comparison between the vaporisation of water and heptane in an unsaturated soil of two temperatures. Transport in Porous Media, 44, 337-353. 